\title{
Consistency of toddler engagement across two settings ${ }^{\text {th }}$
}

\author{
Cecília Aguiar $^{\mathrm{a}, *}$, R.A. McWilliam ${ }^{\mathrm{b}}$ \\ a Faculty of Psychology and Educational Sciences, University of Porto, Portugal \\ b Siskin Children's Institute, Chattanooga, TN, USA
}

\section{A R T I C L E I N F O}

\section{Article history:}

Received 26 May 2010

Received in revised form 9 April 2012

Accepted 22 April 2012

\section{Keywords:}

Consistency

Sophisticated engagement

Toddlers

Responsiveness

Center-based child care quality

\begin{abstract}
A B S T R A C T
This study documented the consistency of child engagement across two settings, toddler child care classrooms and mother-child dyadic play. One hundred twelve children, aged $14-36$ months $(M=25.17$, $S D=6.06$ ), randomly selected from 30 toddler child care classrooms from the district of Porto, Portugal, participated. Levels of engagement were coded, and sophisticated engagement, but not nonengagement, was consistent across settings. Consistency in children's sophisticated engagement was primarily accounted for by chronological age. Children spent more time in sophisticated behaviors and less time nonengaged during mother-child dyadic play than in center-based child care. For sophisticated engagement, effects of child predictors were stronger than effects of environmental features; whereas for nonengagement, effects of environmental features were stronger than effects of child predictors. Findings suggest children's sophisticated engagement may be generalizable across settings, as a function of age, whereas their nonengagement is most likely context dependent.
\end{abstract}

(ㄷ) 2012 Elsevier Inc. All rights reserved.
Young children should spend their time actively playing or participating in the activities that take place in their natural environments rather than spending time unoccupied or displaying undesirable behaviors such as crying, hitting, or destroying materials. This idea is at the core of child engagement, defined by McWilliam and Bailey (1992) as the amount of time children spend interacting with the environment, in a developmentally and contextually appropriate manner, at different levels of competence. This definition embeds both the quantity and quality of children's behaviors and is linked to an exhaustive operationalization of the engagement construct (McWilliam \& de Kruif, 1998), including a hierarchy of cognitive sophistication.

Although best known in the field of early intervention/early childhood special education, child engagement is relevant for all children. In fact, the National Association for the Education of Young Children (2009) acknowledges child engagement as a key experience in early childhood programs serving children from birth through age 8 and encourages teachers to foster children's

\footnotetext{
is This article was based on data included in the first author's doctoral dissertation, supervised by Professor Joaquim Bairrão (1935-2007). This study is part of a research project titled The quality of child interactions in family and day care settings and its influence on children's sociocognitive development, developed by the Center of Psychology of the University of Porto, and supported by grants from the Fundação para a Ciência e a Tecnologia (POCTI/PSI/35207/2000 and POCTI/BD/8317/2002).

* Corresponding author at: UIPCDE, ISPA - University Institute; ISCTE - University Institute of Lisbon, Avenida das Forças Armadas, 1649-026 Lisboa, Portugal. Tel.: +351217903 201; fax: +351217964710

E-mail addresses: caguiar@ispa.pt, cecilia.rosario.aguiar@iscte.pt (C. Aguiar).
}

engagement in learning as part of their efforts to create a caring community of learners.

Child engagement has been considered both a necessary condition for learning to occur (McWilliam, Trivette, \& Dunst, 1985) and a mediator of learning (McWilliam \& Bailey, 1992). Specifically, Raspa, McWilliam, and Ridley (2001) have hypothesized the mediational role of engagement in explaining the relationship between child care quality and children's developmental outcomes. In examining this hypothesis, researchers of early childhood engagement have focused on establishing links between engagement and developmental outcomes (e.g., Pinto, Barros, Aguiar, Pessanha, \& Bairrão, 2006; Pinto, Nunes, Cruz, \& Aguiar, 2006) and on investigating the association between child care quality and engagement (Raspa et al., 2001), while identifying the predictors of engagement in early childhood classrooms.

These efforts, based mostly on cross-sectional correlational designs, have suggested that both child and classroom characteristics are associated with child engagement outcomes. Child characteristics associated with individual engagement outcomes include developmental and chronological age (Aguiar, Cruz, Barros, \& Bairrão, 2005; de Kruif \& McWilliam, 1999), disability status (McWilliam \& Bailey, 1992, 1995), and temperament or individual style (de Kruif, McWilliam, \& Ridley, 2001). Classroom characteristics associated with children's observed engagement include both structure and process variables such as adult-child ratio (Dunst, McWilliam, \& Holbert, 1986; Raspa et al., 2001), teacher assignments in the classroom (Casey \& McWilliam, 2005), classroom structure (McWilliam \& Bailey, 1995), teachers' behaviors (de Kruif et al., 2001; McWilliam, Scarborough, \& Kim, 2003; Pinto, 2006; 
Raspa et al., 2001), and overall classroom quality (e.g., Raspa et al., 2001). The existing literature on the variables associated with child engagement does not address dynamic mesosystem relations between the quality of children's experiences in one particular setting and children's engagement outcomes in other settings (e.g., Aviezer, Sagi-Schwartz, \& Koren-Karie, 2003).

Although used as an indicator of child care and early intervention quality (e.g., Almeida, 2007; Grande, 2010; Pinto, 2006; Raspa et al., 2001), the broad-based multidimensional construct of engagement has been measured essentially as a generalized characteristic (see Yoder \& Symons, 2010), with researchers computing individual participant scores by averaging across multiple observation sessions (see McWilliam \& Ware, 1994) or measuring typical engagement through the report of caregivers who have extensive knowledge of the child's behavioral patterns (e.g., de Kruif \& McWilliam, 1999). However, it is not entirely clear where engagement falls on the continuum from context dependent to generalized (see Yoder \& Symons, 2010). This study was primarily designed to investigate the consistency of children's engagement across two diverse settings, toddler child care classrooms and mother-child dyadic play, while comparing the mean level of selected engagement outcomes in both settings. These data should provide more information on the immutability of engagement behavior. Child and context predictors, including features of the immediate and contrasting setting, were also examined.

The choice of mother-child dyadic play as a measurement context was based on two considerations. First, mother-child dyadic interactions during the first years of life are important for development (e.g., Shonkoff \& Phillips, 2000). Second, research has established links between mother-child dyadic play, as opposed to solitary play or play with other adults, and the sophistication of toddlers' behaviors (e.g., Fiese, 1990; Moreira, 2006). Child engagement has been previously used as an outcome measure for assessing the effects of different adult interaction styles, in dyadic situations (e.g., Girolametto, Verbey, \& Tannock, 1994; Kim \& Mahoney, 2004; Lussier, Crimmins, \& Alberti, 1994). Findings from those studies have consistently established positive links between responsive behaviors and the amount or sophistication of children's engagement.

We based our main research hypothesis on the assumption that child engagement is predominantly a generalized tendency to behave and, therefore, we expected children to maintain their relative rank in engagement across settings. Because both empirical data (e.g., Fiese, 1990) and theory (Bronfenbrenner, 2001) support the assumption that the complexity of children's play and engagement varies as a function of context, however, we also expected children to spend more time engaged in sophisticated behaviors and less time nonengaged during mother-child dyadic play situations. We based the selection of sophisticated engagement and nonengaged behavior - the behaviors at the highest and lowest ends of the engagement developmental hierarchy, respectively - on previous research reporting moderate or strong associations between these specific engagement outcomes (but not middle-level engagement outcomes) and children's concurrent developmental outcomes (e.g., Pinto, Barros, et al., 2006). Therefore, in this paper, we focus on the two categories of engagement that, most likely, have the greatest impact on learning and development, assuming that the greatest value in intervention is found in minimizing nonengagement and maximizing sophisticated engagement (McWilliam \& Casey, 2008).

Regarding the hypotheses related to the second goal, we expected children's characteristics, such as chronological age and individual style, to be the strongest predictors of child engagement outcomes in both settings, although we also expected to find moderate associations between children's engagement outcomes and selected features of each setting (i.e., classroom overall quality and mother's responsiveness). In addition, we expected to find small effects of child care classroom quality on children's engagement during mother-child dyadic play and small effects of mothers' interactive behaviors during mother-child dyadic play on children's engagement in child care classrooms.

Confirmation of these research hypotheses will provide information on the stability of children's individual ranks and engagement levels across settings, contributing to additional knowledge about the nature of engagement. The extent of this stability might inform the field about the representativeness of child engagement measured in a single context, which could have implications for research design and measurement decisions in future studies.

\section{Method}

\subsection{Participants}

Participating in this study were 112 children (50\% girls), aged 14-36 months, attending 30 child care classrooms from 15 private child care centers ( 11 nonprofit and 4 for profit) in the district of Porto, Portugal. These children were recruited from the 120 participants of a broader research project on the quality of children's interactions in family and child care settings and its impact on children's engagement and developmental outcomes. Sampling procedures for the recruitment of child care centers and classrooms are available from Pessanha, Aguiar, and Bairrão (2007). Classroom group size ranged from 8 to 25 children $(M=15.73, S D=5.07)$, and the number of adults in the classroom ranged from 1 to 5 $(M=2.43, S D=1.01)$. Observed adult-child ratio ranged from $1: 4$ to $1: 18(M=1: 7.6, S D=3.35)$. Classrooms for older toddlers (usually between 24 and 36 months) had more children per adult ( $M=8.92$, $S D=3.94)$ than classrooms for younger toddlers $(M=6.33, S D=2.02$; $t(28)=-2.27, p=.03, d=0.83)$.

Sampling procedures of children within the broader research project required 2 boys and 2 girls without disabilities to be randomly selected in each of two classrooms per center, for a total of 60 boys and 60 girls. For this particular study, 8 children were excluded because they were older than 36 months. Informed consent was obtained from all participating parents, but no institutional review boards were in existence in Portugal at the time of the study.

Participating children's chronological age averaged 25.17 months ( $S D=6.06$ ), with $48.2 \%$ of children aged between 14 and 24 months. Families' monthly income ranged from $324.22 €$ to $2618.69 €(M=1335.40, S D=743.27)$. Mothers' age ranged from 18 to 42 years $(M=30.79, S D=5.21)$ and mothers' education (i.e., number of years in school that resulted in a passing grade or number of years required to obtain the highest school/academic degree) ranged from 0 to 17 years $(M=10.65, S D=4.53)$, with $28 \%$ of mothers having a university degree. As only $15 \%$ of Portuguese women have a university degree (Instituto Nacional de Estatística, 2012), this sample, despite its heterogeneity, may be considered relatively advantaged. Eighty-two percent of participating mothers were married or lived with a partner.

\subsection{Measures}

\subsubsection{Mothers' interactive behaviors}

Mothers' interactive behaviors were assessed with the Portuguese translation and adaptation of the Teaching Styles Rating Scale (TSRS; McWilliam, Scarborough, Bagby, \& Sweeney, 1998). This rating scale, designed for capturing the quality of early childhood teachers' interactive behavior, was adapted to capture mothers' interactive behavior in mother-child dyadic play situations (Cruz, Aguiar, \& Barros, 2004). The TSRS is composed of 20 
Table 1

Description of the Teaching Styles Rating Scale items, adapted for rating adults' behavior during dyadic play situations.

\begin{tabular}{|c|c|}
\hline Items & Definition \\
\hline \multicolumn{2}{|l|}{ Teaching behaviors } \\
\hline Redirects & $\begin{array}{l}\text { Getting the child to do something different } \\
\text { from what he/she is doing. Stopping the } \\
\text { child's behavior or interrupting the child's } \\
\text { current engagement }\end{array}$ \\
\hline Introduces & $\begin{array}{l}\text { Giving the child who is not engaged } \\
\text { something to do }\end{array}$ \\
\hline Elaborates & $\begin{array}{l}\text { Providing information to expand on the } \\
\text { child's engagement, without eliciting } \\
\text { behavior }\end{array}$ \\
\hline Follows & $\begin{array}{l}\text { Eliciting verbal or behavioral responses } \\
\text { related to what the child is already doing }\end{array}$ \\
\hline Informs & $\begin{array}{l}\text { Providing nonelaborative information, } \\
\text { telling stories, singing }\end{array}$ \\
\hline Acknowledges & $\begin{array}{l}\text { Acknowledging the child without } \\
\text { elaborating on what he/she is doing and } \\
\text { without helping (includes imitation) }\end{array}$ \\
\hline Praises & $\begin{array}{l}\text { Praising the child enthusiastically. Conveying } \\
\text { pleasure or admiration for the child, the } \\
\text { child's behaviour, or the child's product }\end{array}$ \\
\hline \multicolumn{2}{|r|}{ a d } \\
\hline Activity level & $\begin{array}{l}\text { Amount of energy exerted to meet the child's } \\
\text { needs }\end{array}$ \\
\hline Positive expression & $\begin{array}{l}\text { Smiling and using a pleasing voice inflection } \\
\text { when communicating }\end{array}$ \\
\hline Negative expression & $\begin{array}{l}\text { Never sounding grouchy or negative when } \\
\text { communicating }\end{array}$ \\
\hline Visual involvement & $\begin{array}{l}\text { Looking at the child and visually following } \\
\text { his/her activities }\end{array}$ \\
\hline Physical responsiveness & Amount of physical contact with the child \\
\hline Emotional responsiveness & $\begin{array}{l}\text { Responding to the child in a warm and } \\
\text { nurturing manner }\end{array}$ \\
\hline Consistency of interactions & $\begin{array}{l}\text { Responding to the child in a highly } \\
\text { consistent, predictable manner }\end{array}$ \\
\hline $\begin{array}{l}\text { Responsiveness toward } \\
\text { children's interests }\end{array}$ & Following the child's interests \\
\hline Child-directedness & $\begin{array}{l}\text { Letting the child dictate the pace and the } \\
\text { activities }\end{array}$ \\
\hline Tone & $\begin{array}{l}\text { Communicating in a bossy or controlling } \\
\text { manner }\end{array}$ \\
\hline $\begin{array}{l}\text { Developmental } \\
\text { appropriateness }\end{array}$ & $\begin{array}{l}\text { Gearing activities and content to the child's } \\
\text { developmental level }\end{array}$ \\
\hline
\end{tabular}

Adapted from McWilliam et al. (1998).

items organized in two subscales, one for teaching behaviors and one for affect. The first consists of seven items rated on a 7-point scale with four anchors ( $1=$ never, $3=$ occasionally, $5=$ frequently, $7=$ most of the time); the second consists of 13 items rated on a 5point scale with three item-specific anchors for the odd-numbered points, with higher ratings reflecting more positive affect. In this study, two items of the affect scale concerning children with special needs were excluded because only typically developing children participated in the study. Table 1 provides a brief description of the TSRS items, as used in this study. Adaptations of the original scale were limited to rephrasing items by using the singular form (i.e., replacing children with "child") and adding examples on anchors 1 and 5 on the affect subscale items. The first author of the current paper translated the TSRS into Portuguese, and researchers on the larger study revised it. That team consisted of three doctoral-level specialists in early child care and education. Detailed discussion of coding criteria with the first author of the original English version did not signal any translation issues.

\subsubsection{Child engagement}

Child engagement was coded using the Portuguese translation of the Engagement Quality Observation System (E-Qual III; McWilliam \& de Kruif, 1998; Pinto, Aguiar, Barros, \& Cruz, 2004). The E-Qual III was designed for capturing children's engagement in child care classrooms. It is a momentary time-sampling procedure in which child engagement is coded every $15 \mathrm{~s}$, during $15-\mathrm{min}$ observation sessions (for a total of 60 intervals at each session). In each observation, two codes are entered: a code for the engagement level (i.e., the quality of the child's behavior) and a code for the engagement type (i.e., the target or focus of the child's behavior). At the end of each observation session, frequencies of each code are summed and the result is divided by the total number of observations, resulting in an estimate of the percentage of time spent in each engagement level and type.

Nine mutually exclusive and exhaustive engagement levels are organized in a developmental hierarchy. Previous studies have shown that some of the codes can be reliably and validly grouped, as will be described later. The nine levels are persistent behavior (i.e., problem solving), symbolic behavior (i.e., decontextualized behavior, including pretend play and referent-free language), encoded behavior (i.e., use of understandable language), constructive play (i.e., manipulation of objects in a intentional manner to create or build), differentiated behavior (i.e., active participation that does not meet criteria for higher or lower sophistication levels), focused attention (i.e., sustained attention at one feature of the environment for at least $3 \mathrm{~s}$ ), undifferentiated behavior (i.e., repetitive behavior), casual attention (i.e., attention to a sequence or range of events, objects, or people), and nonengagement (i.e., passive or active undesirable behavior such as lack of occupation, crying, or aggressive or destructive acts; see McWilliam \& Casey, 2008). In this study, only two engagement levels were considered because previous studies (e.g., Pinto, Barros, et al., 2006) had shown they were the most sensitive to predictors: sophisticated engagement (sum of persistent, symbolic, encoded, and constructive behavior) and nonengagement.

\subsubsection{Child care quality}

Assessments of classroom child care quality were made using the Portuguese translation of the Infant/Toddler Environment Rating Scale (ITERS; Harms, Cryer, \& Clifford, 1990/1996), which measures the global quality of care provided in group settings for infants and toddlers up to 30 months of age. The ITERS is an ordinal measure, consisting of 35 items, organized in seven categories: furnishings and display for children, personal care routines, listening and talking, learning activities, interaction, program structure, and adult needs. Each item is presented as a 7-point scale, with descriptors for 1 (inadequate), 3 (minimal), 5 (good), and 7 (excellent). In this study, Cronbachs' alpha coefficient for the overall score was .80. Only 33 items were used: items 31 (provisions for exceptional children) and 23 (water and sand play) were excluded because the former was scored only in one classroom and the latter had no score variance.

\subsubsection{Child temperament}

Children's personal style or temperament characteristics were determined with the Portuguese translation of the Childhood Personality Scale, developed by Dibble and Cohen (1974). Translation procedures included back-translation by an independent researcher and comparison of the original English version with the back-translation, to maximize semantic equivalence. No significant points of divergence were noted. Composed of 48 behavioral items assessed on a 7 -point scale (from $0=$ never to $6=$ always), this rating scale can be used with parents or professionals to assess the global personality and competence of preschool-aged children. The original factorial structure consisted of five dimensions that explained $42.8 \%$ of the total variance (Cohen, Dibble, \& Graw, 1977): Attention, Behavior Modulation, Socialization, Zestfulness, and Verbal and Emotional Expressiveness.

The principal component analysis reported by Pinto (2006), using a Portuguese sample of 222 children between 12 and 49 
months of age $(M=27.12, S D=7.33)$, including the 112 children that participated in this study (see also Pinto, Cruz, \& Bairrão, 2004), yielded a factor structure composed of four components explaining $47 \%$ of the variance. Factor 1, named Sociability/Adaptability, explained $18.82 \%$ of the variance and consisted of 17 items related to verbal expressiveness, positive humor, cooperation with adults, and positive reaction to novelty $(\alpha=.89)$. Factor 2 , named Attention, explained $9.94 \%$ of the variance and consisted of 8 items related to prolonged involvement in activities and persistence $(\alpha=.89)$. Factor 3, designated Socioemotional Control, explained $9.16 \%$ of the variance and consisted of 10 items related to aggressive or inappropriate behavior and excessive movement, among other self-regulation issues $(\alpha=.81)$. Finally, Factor 4 , named Approach/Withdrawal, explained $9.11 \%$ of the variance and consisted of 11 items related to avoidance, shyness, passivity, and lack of enthusiasm $(\alpha=.79)$. In this study, we used these four components, with higher scores reflecting positive characteristics.

\subsubsection{Context structural information}

Demographic information on mothers, families, and children was collected through the Family Questionnaire (European Child Care and Education Study Group [ECCE] Study Group, 1997a). Information on early education teachers' characteristics and toddler classrooms were collected through the Preschool and Daycare Structure Characteristics Questionnaire (ECCE Study Group, 1997b).

\subsection{Procedure}

\subsubsection{Mothers' interactive behaviors}

Each mother was asked to come to the child care center attended by his or her child, on three different days, at a time convenient for her (usually at arrival or departure), to participate in three dyadic play sessions. She was instructed to play with her child as she would at home and was encouraged to try exploring all the toys available in a box provided by the research team. The toy box consisted of a set of stacking rings, a shape sorter, two books, a set of plastic cups, plates and spoons (or forks and knifes), three small plastic cars, a car track rug, eight wooden blocks, a doll, a comb, two tissue napkins, a ball, and a puzzle. Age-appropriate toys were selected, except that the puzzle required higher-level skills than the typical skills of the participants' age group, to capture how developmentally appropriately mothers interacted with their children when they had a developmentally advanced toy.

After 10 min of play, the observer asked each mother to tell the child to put the toys back in the box. The session finished five minutes after this instruction and it took place in a room made available by the center, on a carpet placed on the floor. The clean-up portion of the observations was included with two related purposes: to include a familiar task that could prompt mothers' directiveness and, therefore, enhance the likelihood of capturing differences among mothers and to increase the comparability between engagement observed in mother-child dyadic play and in child care classrooms, as observations of engagement in child care classrooms were conducted during free play as well as structured activities. All sessions were videotaped. After data collection, the 336 videotaped mother-child dyadic play sessions were rated using the 18 TSRS items. Scores for each session reflect observers' ratings of mothers' behavior during the entire $15 \mathrm{~min}$, including both the play and clean-up tasks.

To reduce the data, we analyzed the internal consistency of TSRS scores. Four items were eliminated (introduces, activity level, physical contact, visual contact) because of small correlations with the total score. We also converted the affect scores from a 5-point scale into a 1-7 scale, to be able to analyze across all TSRS scores, rather than having to keep the teaching and affect items separate. Scores on redirects were negatively correlated with the total score $(r=-.50)$ and, therefore, were reversed to ensure direction consistency. The TSRS defines redirects as adult behavior that interrupts the child's current engagement and that captures instances of mother's directive behavior aimed at replacing children's appropriate behavior with other behavior.

We obtained a single composite variable composed of 14 maternal interactive behaviors (consisting of 5 teaching behaviors and 9 items related to affect): redirects (inverted), elaborates, follows, informs, acknowledges, praises, positive expression, absence of negative expression, emotional responsiveness, consistency, responsiveness toward child's interests, absence of child-directedness, positive tone, and developmental appropriateness. This procedure reduced the number of predictor variables related to mothers' interactive behaviors to a minimum, to increase the statistical power of subsequent analyses, while ensuring data interpretability and reliability. The internal consistency of this new variable, named Stimulating and Affective Responsiveness, computed with Cronbach's alpha, was .91. We conducted interrater agreement checks in $25 \%$ of available sessions (85 observation sessions). For the 14 items included in this composite variable, mean interobserver within-1-point percent agreement was 94.96 $(S D=3.97)$ and mean weighted kappa was .43. Data presented in this study were computed as mean scores across the three sessions available for each child. The mean intraclass correlation coefficient across sessions for the 14 items was .70 .

\subsubsection{Child engagement}

Prior to data collection, all coders were trained to $90 \%$ interobserver agreement in all codes. The same level of agreement was established with the E-Qual III mastertape developed by the authors of E-Qual III, which suggests the conceptual equivalence of the Portuguese translation and the comparability of data across the two countries.

1.3.2.1. Child engagement in child care. Each child was observed live, in the child care classroom, during six 15-min sessions, conducted on 6 different days: two observation sessions during structured activities and four observation sessions during free play activities in the classroom. Teachers had previous knowledge that the children would be observed but otherwise they were encouraged to conduct daily activities as usual. Data from the six sessions per child were used to compute a mean score for each observed behavior. Results estimate the percentage of time each child spent on each engagement behavior across the two types of activities. Mean interobserver percent agreement (across 171 agreement sessions) was $99.48 \%$ for sophisticated engagement ( $M$ kappa $=.75$ ) and $95.96 \%$ for nonengagement ( $M$ kappa $=.77$ ). Previously, Raspa et al. (2001) reported an average kappa coefficient of .63, across all E-Qual III codes, and de Kruif and McWilliam (1999) reported a mean kappa of .43 for the nonengagement code.

1.3.2.2. Child engagement in mother-child dyadic play. The 336 videotaped sessions of mother-child dyadic play were used for coding individual child engagement during mother-child dyadic play situations. Following the procedure adopted for the coding of individual child engagement in child care, each observation session was divided into 15-s intervals, at the end of which the coder (alerted by an audio signal from a cassette player with earphones) recorded the code of the most recent behavior. Mean interobserver percent agreement (based on 85 sessions) was $98.00 \%$ for sophisticated engagement ( $M$ kappa $=.72$ ) and $99.35 \%$ for nonengagement ( $M$ kappa =.58). Note that nonengagement in this particular setting was rather infrequent, which could have attenuated kappa 
values, as occurrence base rate affects chance agreement (see Yoder \& Symons, 2010).

\subsubsection{Child care quality}

Information on training and data collection procedures for child care quality measurement are available from Pessanha et al. (2007).

\subsubsection{Child temperament}

The Childhood Personality Scale was rated by the lead teacher of the classroom attended by each child, at her convenience, and later returned to the research team.

\subsubsection{Context structural information}

Information on the Family Questionnaire was collected through an interview, during a home visit. The Preschool and Daycare Structure Characteristics Questionnaire was administered during an interview with the classroom teacher.

\subsection{Data analyses}

To investigate the consistency of children's engagement across settings, we conducted two types of analyses. First, we computed Spearman rank order correlations, because normality assumptions were violated, among engagement outcomes. These correlations tested the hypothesis that children would maintain their relative rank in the percentage of time spent in sophisticated engagement and nonengagement across settings. Second, we computed Wilcoxon signed-rank tests to test the hypothesis that children's engagement levels would differ across settings, including the $d$ effect size estimate recommended by Cohen (1988).

To investigate the predictors of children's engagement across settings, we conducted a series of hierarchical linear model analyses, using the statistical software HLM (Raudenbush, Bryk, \& Congdon, 2004). Four sets of child outcomes were examined: sophisticated engagement in child care, nonengagement in child care, sophisticated engagement in mother-child dyadic play, and nonengagement in mother-child dyadic play. The same covariates were used in all analyses: child care classroom quality, mother's responsiveness, child chronological age, and four dimensions of children's temperament. Previous analysis indicated that child gender could be excluded from the models because it was not associated with the remaining variables. All variables were centered on the grand mean. For each model, interaction terms between mothers' interactive behaviors and child care quality were tested but did not yield statistically significant results so were dropped from the analyses.

To provide a context for interpreting the findings from HLM, effect sizes were computed as the product of the unstandardized coefficient and the standard deviation of the predictor divided by the standard deviation of the outcome (see Burchinal, Roberts, Zeisel, Hennon, \& Hooper, 2006). As suggested by Burchinal and colleagues, and following Cohen's guidelines (1988), these indexes were interpreted according to the following criteria: .10 was considered a small effect, .30 was considered a moderate effect, and .50 was considered an important effect. Interpretation of statistical significance for all results was made using an alpha value of .05. The data set used in this study had no missing data.

\section{Results}

\subsection{Consistency of children's engagement across settings}

As shown in Table 2, results of Spearman rank order correlations indicated a strong positive association between sophisticated engagement in mother-child dyadic play and sophisticated engagement in child care classrooms and no association between nonengagement in center-based child care and nonengagement in mother-child dyadic play. Because both sophisticated engagement in child care classrooms and sophisticated engagement in child care were highly correlated with children's chronological age, partial correlation was used to explore the relationship between these engagement outcomes, while controlling for children's chronological age. To ensure no violation of normality assumptions of partial correlation (Pallant, 2010), a square root transformation of scores of sophisticated engagement in child care classrooms was computed for this particular analysis. Results suggested that controlling for children's age had a considerable effect on the strength of the association between sophisticated engagement in child care classrooms and children's engagement in mother-child dyadic play: $r_{\mathrm{ab} . \mathrm{c}}=.20$, $p=.02$, where $r$ is the partial correlation of sophisticated engagement in child care classrooms (a) and sophisticated engagement in mother-child dyadic play (b), with the effect of chronological age (c) removed.

Results of Wilcoxon signed-rank tests for comparing levels of child engagement across settings revealed a statistically significant difference between the percentage of time spent in sophisticated engagement in child care classrooms and in mother-child dyadic play $(z=-9.19, p<.001, d=2.00)$ as well as a statistically significant difference between the percentage of time spent nonengaged in both settings $(z=-9.13, p<.001, d=2.13)$. The magnitude of these effects was noteworthy, with levels of sophisticated engagement approximately four times greater and levels of nonengagement approximately six times lower in mother-child dyadic play (see Table 2). The two engagement categories considered in this analysis accounted for about $20 \%$ of children's time in child care classrooms and for about $38 \%$ of children's time during mother child dyadic play. They are at opposite ends of the engagement hierarchy, meaning that the remaining time was spent on middle-level engagement behaviors such as differentiated engagement (i.e., conventional behavior) and paying attention.

Descriptive statistics on child care quality, as measured by the ITERS $(M=2.60, S D=0.45)$, indicated the existence of average poor or inappropriate quality in the center-based classrooms attended by participating children (as previously reported by Pessanha et al., 2007). ITERS scores ranged between 1.76 and 3.47 , with only $20 \%$ of participating classrooms obtaining scores equal to or above 3 .

\subsection{Variables associated with child engagement in center-based toddler child care classrooms}

As shown in Table 3, only two child characteristics were associated with sophisticated engagement in child care classrooms: children's chronological age (large positive effect) and children's sociability/adaptability (moderate positive effect). Child care quality and the remaining covariates were not associated with percentages of time spent in sophisticated engagement in child care. Children's chronological age (small negative effect) and center-based child care quality (moderate negative effect) were associated with nonengagement in child care classrooms (see Table 3).

\subsection{Variables associated with child engagement in mother-child dyadic play}

Results shown in Table 4 suggested that children's chronological age and children's sociability/adaptability were associated with sophisticated engagement in mother-child dyadic play, with large and small positive effects, respectively. Mothers' responsiveness also had a small positive association with sophisticated engagement in mother-child dyadic play. Hierarchical-linearmodel results for the variables associated with nonengagement in mother-child dyadic play (see Table 4), indicated that children's 
Table 2

Summary of Spearman rank order intercorrelations, means, standard deviations, and ranges for child level variables.

\begin{tabular}{|c|c|c|c|c|c|c|c|c|c|c|}
\hline & 1 & 2 & 3 & 4 & 5 & 6 & 7 & 8 & 9 & 10 \\
\hline 1. Sophisticated eng. in dyadic play & - & & & & & & & & & \\
\hline 2. Sophisticated eng. in child care & $.69^{*}$ & - & & & & & & & & \\
\hline 3. Nonengagement in dyadic play & $-.47^{*}$ & $-.26^{*}$ & - & & & & & & & \\
\hline 4. Nonengagement in child care & $-.27^{*}$ & $-.42^{*}$ & .14 & - & & & & & & \\
\hline 5. Child chronological age & $.82^{*}$ & $.74^{*}$ & $-.41^{*}$ & $-.31^{*}$ & - & & & & & \\
\hline 6. Child sociability/adaptability & $.35^{*}$ & $.49^{*}$ & -.10 & $-.21^{*}$ & $.31^{*}$ & - & & & & \\
\hline 7. Child attention & .18 & $.27^{*}$ & -.07 & $-.27^{*}$ & .18 & $.57^{*}$ & - & & & \\
\hline 8. Child socioemotional control & $.22^{*}$ & .13 & -.10 & $-.32^{*}$ & $.22^{*}$ & .08 & $.38^{*}$ & - & & \\
\hline 9. Child approach/withdrawal & $.21^{*}$ & .18 & -.09 & -.14 & $.28^{*}$ & $.44^{*}$ & $.40^{*}$ & .17 & - & \\
\hline 10. Mothers' responsiveness & $.36^{*}$ & .16 & $-.43^{*}$ & $-.20^{*}$ & $.32^{*}$ & .09 & $.20^{*}$ & $.27^{*}$ & -.00 & - \\
\hline$M$ & 35.96 & 7.71 & 2.00 & 12.55 & 25.17 & 4.08 & 3.59 & 3.71 & 4.51 & 4.54 \\
\hline$S D$ & 18.39 & 7.72 & 2.61 & 6.50 & 6.06 & 0.87 & 1.04 & 0.96 & 0.81 & 0.57 \\
\hline Range & 4.04-81.11 & $0.00-36.56$ & $0.00-12.35$ & $1.67-36.31$ & $14.00-36.00$ & $2.19-5.81$ & $0.75-5.63$ & $1.50-5.80$ & $2.09-6.00$ & $2.52-5.71$ \\
\hline
\end{tabular}

Table 3

Summary of hierarchical linear model results for variables associated with child engagement in center-based child care classrooms.

\begin{tabular}{|c|c|c|c|c|c|c|}
\hline & \multicolumn{3}{|c|}{ Sophisticated } & \multicolumn{3}{|c|}{ Nonengagement } \\
\hline & $B$ & se & $E S^{\mathrm{a}}$ & $B$ & se & $E S^{\mathrm{a}}$ \\
\hline Intercept & $7.96^{*}$ & 0.68 & & $12.44^{*}$ & 0.59 & \\
\hline Child care quality & 2.37 & 2.02 & .14 & $-5.56^{*}$ & 1.34 & .38 \\
\hline Mother's responsiveness & -0.74 & 0.88 & .05 & -0.11 & 0.99 & .01 \\
\hline Child chronological age & $0.75^{*}$ & 0.13 & .59 & $-0.25^{*}$ & 0.11 & .23 \\
\hline Child sociability/adaptability & $3.06^{*}$ & 0.82 & .34 & 1.06 & 0.95 & .14 \\
\hline Child attention & -0.68 & 1.02 & .09 & -1.09 & 0.71 & .17 \\
\hline Child socioemotional control & 0.29 & 0.66 & .04 & -0.91 & 0.51 & .13 \\
\hline Child approach/withdrawal & -1.26 & 0.77 & .13 & -0.68 & 0.71 & .08 \\
\hline
\end{tabular}

a Effect size.

* $p<.05$.

chronological age (small negative effect) and mothers' responsiveness (moderate negative effect) were associated with this child outcome.

\section{Discussion}

\subsection{Consistency of children's engagement across settings}

Results from this study suggest that children's sophisticated engagement meets the cross-setting consistency criterion for a generalized tendency to behave (Yoder \& Symons, 2010), as demonstrated by the noteworthy association between time spent in sophisticated engagement in center-based child care classrooms and time spent in mother-child dyadic play. However, consistency across settings was, to a considerable extent, accounted by the confounding effects of children's age. Such findings indicate that children's ranks on time spent in sophisticated engagement are stable primarily because children's ranks on age are stable.
The magnitude of the association between sophisticated engagement and children's chronological age suggests the developmental nature of the cognitively sophisticated behaviors included in the sophisticated engagement code (see de Kruif \& McWilliam, 1999).

Such relative stability between sites was not found for nonengagement, as indicated by low associations between nonengagement measured in center-based toddler child care classrooms and nonengagement measured in mother-child dyadic play. These results partially confirm our first research hypothesis, because consistency across settings was found for children's sophisticated engagement, owing to the effect of age, but not for nonengagement.

Despite the rank order consistency in children's sophisticated engagement, correlation coefficients indicated some changes across settings. Our second research hypothesis, which anticipated more sophisticated engagement and less nonengagement in mother-child dyadic play than in classroom settings, was confirmed. Consistent with an ecological framework, therefore, absolute scores of children's sophisticated engagement and nonengagement varied as a function of context. Other researchers have

Table 4

Summary of hierarchical linear model results for variables associated with child engagement in mother-child dyadic play.

\begin{tabular}{|c|c|c|c|c|c|c|}
\hline & \multicolumn{3}{|c|}{ Sophisticated } & \multicolumn{3}{|c|}{ Nonengagement } \\
\hline & $B$ & se & $E S^{\mathrm{a}}$ & $B$ & se & $E S^{\mathrm{a}}$ \\
\hline Intercept & $35.94^{*}$ & 1.07 & & $2.00^{*}$ & 0.20 & \\
\hline Child care quality & -2.71 & 2.72 & .07 & 0.29 & 0.52 & .05 \\
\hline Mother's responsiveness & $4.24^{*}$ & 1.29 & .13 & $-1.81^{*}$ & 0.42 & .40 \\
\hline Child chronological age & $2.17^{*}$ & 0.21 & .72 & $-0.09^{*}$ & 0.03 & .21 \\
\hline Child sociability/adaptability & $3.83^{*}$ & 1.15 & .18 & 0.07 & 0.29 & .02 \\
\hline Child attention & -0.58 & 1.15 & .03 & 0.20 & 0.29 & .08 \\
\hline Child socioemotional control & 0.56 & 0.83 & .03 & -0.11 & 0.19 & .04 \\
\hline Child approach/withdrawal & -0.82 & 1.36 & .04 & -0.24 & 0.33 & .07 \\
\hline
\end{tabular}

\footnotetext{
a Effect size.
}

${ }^{*} p<.05$. 
found differential effects of activity context on children's level of play, a construct comparable to engagement in young children (Bornstein, Haynes, O’Reilly, \& Painter, 1996; Cielinski, Vaughn, Seifer, \& Contreras, 1995; Fiese, 1990; Leal, 2003; Mahoney \& Wheeden, 1999). Furthermore, the very first study to examine engagement in this line of research showed differences in engagement between both settings and activities within settings (McWilliam et al., 1985).

Center-based toddler classrooms and mother-child dyadic play situations are clearly not comparable. The opportunities and challenges existing in structured and free play activities in center-based group settings are different from those in dyadic play. Regardless of the specific developmental functions and potential benefits of both settings, widely described in the literature (e.g., National Institute of Child Health and Human Development [NICHD] Early Child Care Research Network, 2005), the differences in child engagement scores between settings suggest more potential for engagement during mother-child dyadic play than in this particular group of center-based toddler child care classrooms. Perhaps this is not surprising considering most toddlers in this study attended lowquality child care classrooms that, on average, did not meet basic health and safety requirements, did not provide sufficient materials to answer children's developmental needs, and presented problems related to individualization (see Aguiar, Bairrão, \& Barros, 2002; Pessanha et al., 2007). Future studies should examine the impact of home quality on engagement.

\subsection{Variables associated with child engagement in center-based toddler child care classrooms}

Our examination of the variables associated with engagement outcomes in center-based child care classrooms indicated that older children and children who were more sociable and expressive spent significantly more time in sophisticated engagement. Additionally, older children and children who attended higher-quality child care classrooms spent significantly less time nonengaged in this group setting. Associations among child characteristics and children's engagement outcomes were expected and are consistent with previous findings from child engagement research (e.g., de Kruif \& McWilliam, 1999). Also expected and consistent with previous research was the moderate negative association between child care quality and children's nonengagement (Raspa et al., 2001).

These findings confirm the strength of the associations between specific child characteristics and children's sophisticated engagement in group child care settings, as anticipated, but do not provide support for the hypothized moderate association between classroom quality and sophisticated engagement. Because research suggests that the magnitude of the association between child care quality and children's developmental outcomes is larger at higher levels of quality than at lower levels (Burchinal, Vandergrift, Pianta, \& Mashburn, 2010), higher-quality child care classrooms might be necessary for correlations between child care quality and children's sophisticated engagement.

Findings on the variables associated with children's nonengagement in center-based child care settings challenge the hypothized strength of the associations among child nonengagement, children's characteristics, and features of the environment: the magnitude of the associations with child care quality exceed the magnitude of the associations with children's age. Consistent with results on (the lack of) cross-setting consistency and with observed differences in the level of children's nonengagement across settings, this finding appears to indicate that children's nonengagement is, most likely, primarily a context-dependent behavior (Yoder \& Symons, 2010).

\subsection{Variables associated with child engagement in mother-child dyadic play}

Variables associated with children's sophisticated engagement and nonengagement in mother-child dyadic play sessions were similar to those in center-based child care classrooms. Specific to engagement outcomes in mother-child dyadic play sessions was the small positive correlation between children's sophisticated engagement and mothers' responsiveness. As hypothesized, children's characteristics were more highly correlated with sophisticated engagement than was the relevant context feature, mothers' responsiveness. Associations between children's nonengagement in mother-child play and children's chronological age as well as associations between children's nonengagement and the contextrelevant feature, mother's responsiveness, had exactly the same magnitude as the associations found in the contrasting setting, with context factors superseding individual characteristics. Once again, therefore, findings support the context-dependent nature of children's nonengagement. The expected associations between the quality of children's experiences in one setting and children's engagement outcomes in another setting, however, were not confirmed, suggesting that how children spend their time is most likely associated with children's personal characteristics (particularly for sophisticated engagement), features of the measurement context (particularly for nonengagement), and other such strong influences.

The small associations between children's sophisticated engagement and mothers' responsiveness in mother-child dyadic play as well as the noteworthy mean differences in the amount of time children spent in sophisticated engagement in the two settings suggest that, despite its relative stability across contexts and its developmental nature, children's sophisticated engagement is likely to increase under certain conditions. Although not causal, findings reported here suggest that individualized, responsive, stimulating, and affectionate interactions may increase young children's opportunities to engage in sophisticated behaviors such as problem solving, pretend play, use of understandable language, and creative manipulation of objects (i.e., sophisticated engagement). Similarly, although causal links cannot be established, such positive adult interactive behaviors may also decrease the likelihood of children's nonengagement. Note, however, that despite the fact that we controlled for children's age and personal characteristics, unaccounted-for child effects could partially explain the association between mothers' behavior and child engagement outcomes.

\subsection{Limitations and strengths}

Some limitations to this study must be acknowledged. First, the context was limited to Portuguese center-based child care classrooms. Second, the type and duration of mother-child dyadic play sessions may raise issues related to the ecological validity of the measurement context. Third, the use of rating scales developed in the U.S. might raise questions about cultural validity. Fourth, the mean interobserver agreement for mother's interactive behaviors and children's nonengagement in mother-child dyadic play could be considered only moderate (see Landis \& Koch, 1977), suggesting caution is warranted in interpreting findings based on these particular variables, despite the fact that we have used mean scores across multiple sessions for mothers interactive behaviors and that reliability of children's nonengagement in mother child dyadic play was probably influenced by its low base rate. Finally, the use of a global measure of quality may be underestimating the associations between child care quality and children's engagement outcomes (see Burchinal et al., 2009). Despite these limitations, this paper has important strengths, such as the use of considerable amounts of observational data in two different settings, an absence of missing data, and diversity in educational level and economic resources 
of participants. Furthermore, despite the previous word of caution on the potential for generalization, the fact that this study reports data on a culturally diverse sample may be considered an important strength.

\subsection{Implications for practice and future research}

Findings from this study extend the knowledge base of child engagement in early childhood settings. We now know that sophisticated engagement and nonengagement vary as a function of context and show different associations with predictors: In both settings considered in this study, child predictors had more influence on the variance in sophisticated engagement and contextual predictors had more for nonengagement. A possible practical implication of these findings is the potential for intervention, as nonengagement might be more likely to change than sophisticated engagement.

A number of strategies for minimizing children's nonengagement and for maximizing time spent in sophisticated engagement have been previously described in the literature, namely rotating toys (McGee, Daly, Izeman, Mann, \& Risley, 1991); breaking up the middle of the classroom, dividing the classroom into zones, and setting up activity centers within a zone, while avoiding wide open spaces (McWilliam \& Casey, 2008); using a zone defense schedule to organize adults (Casey \& McWilliam, 2005); using incidental teaching (McWilliam \& Casey, 2008); and so on. Results from this study suggest that instances of warm and responsive dyadic adult-child interactions may be associated with increases in time spent in sophisticated engagement and decreases in nonengagement.

The need for quality improvements in center-based child care classrooms in the Porto district also emerged as a practical implication of this study. The poor quality observed in participating classrooms as well as the wide range observed in group size and adult-child ratio raise important concerns about children's daily experiences in these settings (see also Barros \& Aguiar, 2010). Adding to these concerns, the recent publication of Ordinance No. 262/2011 (Ministério da Solidariedade e da Segurança Social, 2011) announced increases in the maximum number of children allowed in center-based classrooms serving children up to 3 years old, without a corresponding increase in the number of adults. The number of Portuguese children served by these settings is not negligible: currently, around 33\% of Portuguese children under three years of age attend authorized center-based or home-based nonparental child care (Gabinete de Estratégia e Planeamento, 2010) and, in the district of Porto, $89 \%$ of all infants and toddlers attending authorized nonparental child care are served by center-based child care (Gabinete de Estratégia e Planeamento, 2009).

Future research relating child engagement outcomes to child care quality will probably benefit from a closer alignment of quality measures and children's engagement outcomes (Zaslow et al., 2010). For example, the use of a measure capturing the interaction of teachers with individual children, rather than a measure capturing overall style with any and all children, might be more sensitive to associations between child care quality and children's engagement outcomes.

Finally, future research on children's engagement should address stability over time to deepen our understanding of child engagement outcomes, particularly sophisticated engagement. As hypothesized, this class of behaviors seems to be a reflection of an age-related generalized construct that most likely reflects children's ability to interact with the environment at high levels of competence; however, examination of its trajectory over time may provide useful confirmation of this assumption. Researchers on engagement should give careful consideration to measurement issues of sophisticated engagement, designing structured measurement contexts, and relying on multiple sessions to derive scores
(Yoder \& Symons, 2010). Conversely, as nonengagement does not seem to be consistent across settings, both researchers and practitioners should consider that this type of behavior probably does not provide useful information on what occurs outside the measurement context (Yoder \& Symons, 2010).

\section{Acknowledgments}

The authors express their gratitude to the children, families, and teachers who participated in this study, and to team members Ana Isabel Pinto, Ana Susana Almeida, Joana Cadima, Leen Poppe, Manuela Pessanha, Maria da Paz Mascarenhas, Orlanda Cruz, Patrícia Silva, and Sílvia Barros.

\section{References}

Aguiar, C., Bairrão, J., \& Barros, S. (2002). Contributos para o estudo da qualidade em contexto de creche na área metropolitana do Porto [Contributions to the study of toddler child care in the metropolitan area of Porto]. Infância e Educação: Investigação e Práticas, 5, 7-28.

Aguiar, C., Cruz, O., Barros, S., \& Bairrão, J. (2005). Perfis interactivos maternos e envolvimento das crianças em contexto de creche [Mothers' interactive profiles and child engagement in child care]. In J. Bairrão (Org.), Desenvolvimento: Contextos familiares e educativos (pp. 74-97). Porto, Portugal: LivPsi/Legis.

Almeida, A. S. (2007). Comportamentos interactivos das educadoras e envolvimento das crianças em contexto de creche [Teacher interactive behaviors and children's engagement in infant-toddler center-based child care] (Unpublished master's thesis). Faculty of Psychology and Educational Sciences, University of Porto, Portugal.

Aviezer, O., Sagi-Schwartz, A., \& Koren-Karie, N. (2003). Ecological constraints on the formation of infant-mother attachment relations: When maternal sensitivity becomes ineffective. Infant Behavior \& Development, 26, 285-299.

Barros, S., \& Aguiar, C. (2010). Assessing the quality of Portuguese child care programs for toddlers. Early Childhood Research Quarterly, 25, 527-535. http://dx.doi.org/10.1016/j.ecresq.2009.12.003

Bornstein, M. H., Haynes, O. M., O’Reilly, A. W., \& Painter, K. M. (1996). Solitary and collaborative pretense play in early childhood: Sources of individual variation in the development of representational competence. Child Development, 67, 2910-2929.

Bronfenbrenner, U. (2001). Human development, bioecological theory of. In N. J. Smelser, \& P. B. Baltes (Eds.), International encyclopedia of the social E behavioral sciences (pp. 6963-6970). New York, NY: Elsevier.

Burchinal, P., Kainz, K., Cai, K., Tout, K., Zaslow, M., Martinez-Beck, I., et al. (2009) Early care and education quality and child outcomes. Washington, DC: Office of Planning, Research and Evaluation, Administration for Children and Families, US DHHS, and Child Trends.

Burchinal, M., Roberts, J. E., Zeisel, S. A., Hennon, E. A., \& Hooper, S. (2006). Social risk and protective child, parenting, and child care factors in early elementary schools. Parenting: Science and Practice, 6, 79-113.

Burchinal, M., Vandergrift, N., Pianta, R., \& Mashburn, A. (2010). Threshold analysis of association between child care quality and child outcomes for low-income children in pre-kindergarten programs. Early Childhood Research Quarterly, 25, 166-176. http://dx.doi.org/10.1016/j.ecresq.2009.10.004

Casey, A. M., \& McWilliam, R. A. (2005). Where is everybody? Organizing adults to promote engagement. Young Exceptional Children, 8, 2-10.

Cielinski, K. L., Vaughn, B. E., Seifer, R., \& Contreras, J. (1995). Relations among sustained engagement during play, quality of play, and mother-child interaction in samples of children with Down syndrome and normally developing toddlers. Infant Behavior and Development, 18, 163-176.

Cohen, J. (1988). Statistical power analysis for the behavioral sciences (2nd ed.). Hillsdale, NJ: Erlbaum.

Cohen, D. J., Dibble, E., \& Graw, J. M. (1977). Fathers' and mothers' perceptions of children's personality. Archives of General Psychiatry, 34, 480-487.

Cruz, O., Aguiar, C., \& Barros, S. (2004). Escala de Avaliação dos Estilos de Ensino: qualidades psicométricas dos dados [Teaching Styles Rating Scale: Data psychometric properties]. Psico-USF, 9, 165-171.

de Kruif, R. E. L., \& McWilliam, R. A. (1999). Multivariate relationships among developmental age, global engagement, and observed child engagement. Early Childhood Research Quarterly, 14, 515-536.

de Kruif, R. E. L., McWilliam, R. A., \& Ridley, S. M. (2001). Effects of child characteristics and teacher interaction behaviors on children's observed engagement. Unpublished manuscript, University of North Carolina at Chapel Hill, NC.

Dibble, E., \& Cohen, D. J. (1974). Companion instruments for measuring children's competence and parental style. Archives of General Psychiatry, 30, 805-815.

Dunst, C. J., McWilliam, R. A., \& Holbert, K. (1986). Assessment of preschool classroom environments. Diagnostique, 11, 212-232.

European Child Care and Education Study Group. (1997a). (Family Questionnaire) Questionário da família. University of Porto, Portugal: Faculty of Psychology and Educational Sciences.

European Child Care and Education Study Group. (1997b). (Preschool and daycare structural characteristics questionnaire - Interview with the classroom teacher) 
Questionário de Avaliação das Características Estruturais de Estabelecimentos de Educação Pré-Escolar/Creche. University of Porto, Portugal: Faculty of Psychology and Educational Sciences.

Fiese, B. H. (1990). Playful relationships: A contextual analysis of mother-toddler interaction and symbolic play. Child Development, 61, 1648-1656.

Gabinete de Estratégia e Planeamento. (2009). Carta social: Rede de serviços e equipamentos: Relatório 2009 [Social letter: Services and equipments network: 2009 Report]. Lisboa, Portugal: Ministério do Trabalho e da Solidariedade Social. Retrieved from: http://www.cartasocial.pt/pdf/csocial2009.pdf

Gabinete de Estratégia e Planeamento. (2010). Carta social: Folha informativa: Mais informação sobre a rede de serviços e equipamentos (Carta informativa $n \cdot{ }^{\circ} 4$ ) [Social letter: Informative Brief: More information about the services and equipments network (Informative Brief No. 4)]. Lisboa, Portugal: Ministério do Trabalho e da Solidariedade Social. Retrieved from: http://www.cartasocial.pt/pdf/FI042010.pdf

Girolametto, L., Verbey, M., \& Tannock, R. (1994). Improving joint engagement in parent-child interaction: An intervention study. Journal of Early Intervention, 18, 155-167.

Grande, C. (2010). Estudo do impacto das interacções educadora-criança no envolvimento das crianças com necessidades educativas especiais em contexto de creche $e$ de jardim-de-infância [Study of the impact of teacher-child interactions on children's engagement in infant-toddler center-based child care and preschool] (Unpublished doctoral dissertation). Faculty of Psychology and Educational Sciences, University of Porto, Portugal.

Harms, T., Cryer, D., \& Clifford, R. M. (1996). Escala de Avaliação do Ambiente de Creche [Infant/Toddler Environment Rating Scale - ITERS] (A. I. Pinto, \& T. Grego, Trans.) Faculty of Psychology and Educational Sciences, University of Porto, Portugal (Original work published 1990).

Instituto Nacional de Estatística. (2012). Estatísticas no feminino: Ser mulher em Portugal, 2001-2011 [Statistics in feminine: To be a woman in Portugal, 2001-2011]. Lisboa, Portugal: Author. Retrieved from: http://www.ine.pt/ xportal/xmain?xpid=INE\&xpgid=ine_publicacoes\&PUBLICACOESpub_boui= 136501356\&PUBLICACOESmodo $=2$

Kim, J. M., \& Mahoney, G. (2004). The effects of mother's style of interaction on children's engagement: Implications for using responsive interventions with parents. Topics in Early Childhood Special Education, 24, 31-38.

Landis, J. R., \& Koch, G. G. (1977). The measurement of observer agreement for categorical data. Biometrics, 33, 159-174.

Leal, T. M. (2003). Interaç̧ões educativas na família e no jardim-de-infância [Educational interactions in family and preschool settings] (Unpublished doctoral dissertation). Faculty of Psychology and Educational Sciences, University of Porto, Portugal.

Lussier, B. J., Crimmins, D. B., \& Alberti, D. (1994). Effect of three adult interaction styles on infant engagement. Journal of Early Intervention, 18, 12-24.

Mahoney, G., \& Wheeden, C. A. (1999). The effect of teacher style on interactive engagement of preschool-aged children with special needs. Early Childhood Research Quarterly, 14, 51-68.

McGee, G. G., Daly, T., Izeman, S. G., Mann, L. H., \& Risley, T. R. (1991). Use of classroom materials to promote preschool engagement. Teaching Exceptional Children, 23, 44-47.

McWilliam, R. A., \& Bailey, D. B. (1992). Promoting engagement and mastery. In D. B. Bailey, \& M. Wolery (Eds.), Teaching infants and preschoolers with disabilities (2nd ed., pp. 229-256). New York, NY: Merrill.

McWilliam, R. A., \& Bailey, D. B. (1995). Effects of classroom social structure and disability on engagement. Topics in Early Childhood Special Education, 15, 123-147.

McWilliam, R. A., \& Casey, A. M. (2008). Engagement of every child in the preschool classroom. Baltimore, MD: Paul H. Brookes Publishing.

McWilliam, R. A., \& de Kruif, R. E. L. (1998). Engagement Quality Observation System III (E-Qual III). Chapel Hill, NC: Frank Porter Graham Child Development Center. University of North Carolina at Chapel Hill.

McWilliam, R. A., Scarborough, A. A., Bagby, J. H., \& Sweeney, A. L. (1998). Teaching Styles Rating Scale. Chapel Hill, NC: Frank Porter Graham child Development Center. University of North Carolina at Chapel Hill.

McWilliam, R. A., Scarborough, A. A., \& Kim, H. (2003). Adult interactions and child engagement. Early Education E' Development, 14, 7-27.
McWilliam, R. A., Trivette, C. M., \& Dunst, C. J. (1985). Behavior engagement as a measure of the efficacy of early intervention. Analysis and Intervention in Developmental Disabilities, 5, 59-71.

McWilliam, R. A., \& Ware, W. B. (1994). The reliability of observations of young children's engagement: An application of generalizability theory. Journal of Early Intervention, 18, 34-47.

Ministério da Solidariedade e da Segurança Social. (2011). Portaria n. ${ }^{\circ}$ 262/2011 de 31 de Agosto [Ordinance No. 262/2011 of 31 August]. Diário da República, 1. série-N. ${ }^{\circ}$ 167-31 de Agosto de 2011 (pp. 4338-4343).

Moreira, G. (2006). Avaliação das competências interactivas no domínio cognitivo [Assessment of interactive competencies in the cognitive domain] (Unpublished master's thesis). Faculty of Psychology and Educational Sciences, University of Porto, Portugal.

National Association for the Education of Young Children. (2009). Devel opmentally appropriate practice in early childhood programs serving children from birth through age 8: Position statement. Retrieved from: http://www.naeyc.org/files/naeyc/file/positions/PSDAP.pdf

National Institute on Child Health and Human Development Early Child Care Research Network. (2005). Child care and child development: Results from the NICHD Study of Early Child Care and Youth Development. New York, NY: The Guilford Press.

Pallant, J. (2010). SPSS survival manual: A step by step guide to data analysis using SPSS (4th ed.). Berkshire, England: McGraw Hill.

Pessanha, M., Aguiar, C., \& Bairrão, J. (2007). Influence of structural features on Portuguese toddler child care quality. Early Childhood Research Quarterly, 22, 204-214. http://dx.doi.org/10.1016/j.ecresq.2007.02.003

Pinto, A. I. (2006). O envolvimento da criança em contexto de creche: Os efeitos de características da criança, da qualidade do contexto e das interacções educativas [Child engagement in child care: The effects of child caracteristics, context quality, and educational interactions] (Unpublished doctoral dissertation). Faculty of Psychology and Educational Sciences, University of Porto, Portugal.

Pinto, A. I., Aguiar, C., Barros, S., \& Cruz, O. (2004). O Sistema de Avaliação da Qualidade do Envolvimento III: Um procedimento de avaliação do envolvimento da criança em contexto de creche [The Engagement Quality Observation System III: A procedure for assessing child engagement in child care]. In C. Machado, L. S. Almeida, M. Gonçalves, \& V. Ramalho (Orgs.), Avaliação Psicológica: Formas e Contextos (Vol. X, pp. 441-448). Braga, Portugal: Psiquilíbrios Edições.

Pinto, A. I., Barros, S., Aguiar, C., Pessanha, M., \& Bairrão, J. (2006). Idade desenvolvimental, comportamento adaptativo e envolvimento observado [Developmental age, adaptive behavior, and observed engagement]. Análise Psicológica, XXIV(4), 447-466.

Pinto, A. I., Cruz, O., \& Bairrão, J. (2004). A Escala de Personalidade da Criança: Validação de uma medida do temperamento para crianças [Childhood Personality Scale: Validation of a measure of children's temperament]. In C. Machado L. S. Almeida, M. Gonçalves, \& V. Ramalho (Orgs.), Avaliação Psicológica: Formas e Contextos (Vol. X, pp. 408-414). Braga, Portugal: Psiquilíbrios Ediç̃̃es.

Pinto, A. I., Nunes, C., Cruz, O., \& Aguiar, C. (2006). O Sistema de Avaliação da Qualidade do Envolvimento III - Um estudo comparativo. In C. Machado, L. S. Almeida M. Gonçalves, M. A. Guisande, \& V. Ramalho (Orgs.), Actas da XI Conferência Internacional de Avaliação Psicológica: Formas e Contextos (pp. 807-819). Braga, Portugal: Psiquilíbrios Edições.

Raspa, M. J., McWilliam, R. A., \& Ridley, S. M. (2001). Child care quality and children's engagement. Early Education and Development, 12, 209-224.

Raudenbush, S. W., Bryk, A. S., \& Congdon, R. (2004). HLM 6 for Windows [Computer software]. Lincolnwood, IL: Scientific Software International.

Shonkoff, J., \& Phillips, D. (Eds.). (2000). From neurons to neighbourhoods: The science of early childhood development. Washington, DC: National Academy Press.

Yoder, P., \& Symons, F. (2010). Observational measurement of behavior. New York, NY: Springer Publishing Company.

Zaslow, M., Anderson, R., Redd, Z., Wessel, J., Tarullo, L., \& Burchinal, M. (2010). Quality dosage, thresholds, and features in early childhood settings: A review of the literature. OPRE 2011-5. Washington, DC: Office of Planning, Research and Evaluation, Administration for Children and Families, U.S. Department of Health and Human Services. 